\title{
BMJ Open Cross-sectional study of dengue-related knowledge, attitudes and practices in Villa El Salvador, Lima, Peru
}

\author{
William H Elson, ${ }^{1}$ Emma Ortega, ${ }^{2}$ Michelle Kreutzberg-Martinez, ${ }^{2}$ \\ Frederique Jacquerioz, ${ }^{2}$ Lilia N Cabrera, ${ }^{3}$ Richard A Oberhelman, ${ }^{2}$ \\ Valerie A Paz-Soldan ${ }^{2,3}$
}

To cite: Elson WH, Ortega E, Kreutzberg-Martinez M, et al. Cross-sectional study of dengue-related knowledge, attitudes and practices in Villa El Salvador, Lima, Peru. BMJ Open 2020;10:e37408. doi:10.1136/ bmjopen-2020-037408

- Prepublication history and additional material for this paper are available online. To view these files, please visit the journal online (http://dx.doi. org/10.1136/bmjopen-2020037408).

Received 03 February 2020

Revised 29 June 2020

Accepted 30 June 2020

Check for updates

(C) Author(s) (or their employer(s)) 2020. Re-use permitted under CC BY-NC. No commercial re-use. See rights and permissions. Published by BMJ.

${ }^{1}$ Department of Entomology and Nematology, University of California, Davis, California, USA

${ }^{2}$ Tulane University School of

Public Health and Tropical

Medicine, New Orleans,

Louisiana, USA

${ }^{3}$ Asociacion Benefica PRISMA

Lima, San Miguel, Peru

Correspondence to

Valerie A Paz-Soldan;

vpazsold@tulane.edu

\section{ABSTRACT}

Objectives To describe and quantify the dengue-related knowledge, attitudes and practices of residents in an urban shantytown in Lima, Peru.

Design/setting A cross-sectional survey of adults between 18 and 80 years living in approximately 120 blocks in 0asis, an urban shantytown situated in the lowto-middle income district of Villa El Salvador in Southern Lima. The survey was adapted from an existing survey previously used in Iquitos, Peru, and included questions relating to knowledge of dengue symptoms, transmission, prevention and current mosquito control practices.

Participants A total of 240 surveys were completed with $80 \%$ of respondents being female and approximately $50 \%$ of all respondents describing themselves as housewives.

Results Although $97.9 \%$ of respondents had heard of dengue, only $6.2 \%$ of people knew someone who had experienced the disease. Approximately half (54.2\%) of the respondents knew dengue was transmitted by mosquitoes and $51.7 \%$ were able to identify fever and one other correct symptom of dengue. Female sex was significantly associated with greater symptom knowledge (OR 2.22, 95\% Cl 1.08 to 4.72) and prevention knowledge (OR 2.12, 95\% $\mathrm{Cl} 1.06$ to 4.21). Past or current higher education attendance was significantly associated with symptom knowledge (OR 2.56, 95\% $\mathrm{Cl} 1.25$ to 5.44 ) and transmission knowledge (OR 3.46, 95\% Cl 1.69 to 7.57). Knowledge of dengue was not significantly associated with carrying out practices to control mosquitoes (OR 1.76 $95 \% \mathrm{Cl} 0.87$ to 3.54 ).

Conclusions This population demonstrated baseline dengue knowledge. However, this was incomplete and substantially less when compared with endemic areas. Given the sporadic nature of dengue transmission in Lima, it is not surprising that knowledge of the disease was not associated with carrying out practices to reduce mosquitoes. However, as dengue transmission in Lima is likely to increase, understanding how best to improve public knowledge of the disease and how to translate this into appropriate community action will be a key public health consideration.

\section{INTRODUCTION}

Dengue is a mosquito-borne viral infection caused by one of four distinct serotypes of dengue virus (DENV). It is common in

\section{Strengths and limitations of this study}

- This study uses a dengue-related knowledge, attitudes and practices survey that has been used successfully in a number of studies in Iquitos, Peru.

- We target an urban population of Lima, Peru, where dengue is not endemic but where there is a potential for increased future transmission. This is an understudied group.

- Our study was limited to one site in Lima and could have benefited from further data collection in a range of different locations in Lima thus enabling comparison between districts, including those that have experienced previous dengue outbreaks.

- The community in which this study took place, however, is representative of many socioeconomically similar sites in Lima to which these results could be cautiously extrapolated.

tropical and subtropical regions of the world where its principal mosquito vector, Aedes aegypti, is abundant. There are believed to be around 100 million clinically apparent infections per year. ${ }^{1}$ Approximately $50 \%$ of the global population is estimated to live in areas suitable for dengue transmission, and this burden is expected to grow substantially in the coming 50 years in part due to the impact of climate change and urbanisation. ${ }^{2}$

The Americas contribute substantially to the global burden of dengue with an annual average of approximately 1.5 million cases reported to the Pan American Health Organization (PAHO) between 2014 and 2019 inclusive. ${ }^{3}$ In 2019, over 3 million cases of dengue were reported to PAHO, the highest annual number since records began. ${ }^{4}$ The transmission of DENV in Peru has been well documented since its re-emergence in the early 1990s with cases reported every year since $1990 .{ }^{356}$ The areas of Peru with the highest incidence of dengue are the eastern departments (states) located within the Amazon basin (Loreto, Ucayali and Madre de Dios) 
and coastal departments in the north of the country (Piura, Tumbes, La Libertad and Lambayeque). ${ }^{7}$

In recent years, sizeable outbreaks of dengue have occurred in regions of Peru previously only reporting sporadic autochthonous cases. Between 2000 and 2015, the department of Ica, located $300 \mathrm{~km}$ south of Lima, had reported less than four cases per year. Entomological surveillance detected the presence of $A$. aegypti in Ica in 2015, and an outbreak of dengue occurred the following year with 156 confirmed cases reported to the Peruvian Ministry of Health (MINSA). Transmission has persisted with over 1500 cases reported in $2017 .{ }^{8}$ Since 2000, MINSA has recorded the presence of $A$. aegypti in 41 out of 43 districts in the metropolitan area (province) of Lima where Peru's capital is located, ${ }^{10}$ and a number of dengue outbreaks have occurred. ${ }^{11}{ }^{12}$ However, with a population of 8.8 million and its prominence as a travel hub, the province remains at risk of more substantial dengue transmission in the future. ${ }^{13}$

As part of their global dengue prevention strategy, the WHO recommends an integrated vector management (IVM) approach relying on dengue-specific vector control measures implemented in partnership with local government and communities. ${ }^{14}$ A baseline understanding of the public's knowledge, attitude and practices (KAP) with respect to dengue can help governments define and address local barriers to vector control implementation. KAP surveys relating to dengue have been carried out in many countries, including a number in Latin America. ${ }^{15-23}$ MINSA carried out a survey in 2004 reporting how KAP can influence the successful implementation of public health campaigns. ${ }^{24}$ Since then, they have carried out numerous campaigns to promote and educate the public in relation to dengue and other $A$. aegypti transmitted diseases. ${ }^{25}$ As the impact of dengue varies widely across the country, it is reasonable to expect varying knowledge and practices dependent on the specific location. A previous KAP survey carried out in 2009 in the Peruvian Amazonian city of Iquitos where dengue is endemic revealed that $85.6 \%$ of participants knew that dengue was transmitted by mosquitoes compared with $40 \%-58.4 \%$ in a smaller study in Ica in 2010 prior to the 2015 outbreak. ${ }^{926}$ The Iquitos study highlighted the association of a higher education level and a better understanding of dengue, as well as higher income level being associated with vector control practices that required purchasing power, such as the use of mosquito coils and insecticide sprays. Further evidence also links adequate knowledge of dengue and community empowerment to a reduction of entomological $A$. aegypti indices and rates of dengue. ${ }^{27-29}$

KAP surveys related to dengue have tended to be carried out in communities where dengue is endemic or where ongoing or recent outbreaks have occurred. As the risk of dengue expands to new areas, having an understanding of the population's baseline knowledge could help to better design and implement communitybased interventions specific to this population and could provide insights for many similar communities around

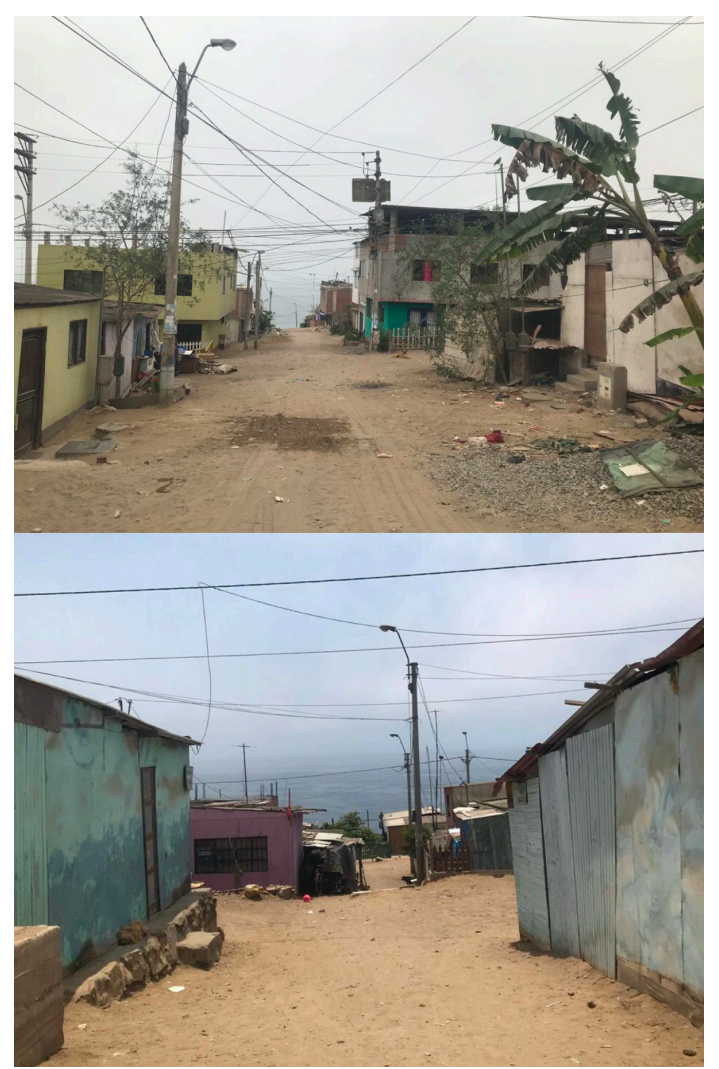

Figure 1 Pictures of Oasis showing nature of housing and local roads.

the globe where dengue may spread. These lessons could have the largest impact in large urban areas such as Lima, where millions of people are at risk. With this in mind, the objective of this manuscript is to examine the denguerelated KAP of participants recruited from an urban shantytown in Lima's southern district of Villa El Salvador.

\section{METHODS}

\section{Study setting}

This cross-sectional study took place in Oasis (figure 1), an urban shantytown located in the low-to-middle income district of Villa El Salvador on the outskirts of southern Lima (estimated population of 450000 in 2015).$^{13}$ Villa El Salvador was initially established as a 'recent settlement' or 'pueblo joven' in the 1970s; Oasis was established slightly later, in the late 1980s and early 1990s. As occurs with settlements that are allowed to remain on the land, individuals eventually replace their straw mat homes for longer term materials, such as wood and bricks and eventually install electricity and water. Some Oasis homes closer to the asphalted main highway are made of bricks, but within blocks, roads are not asphalted, houses are made of chipboard, house roofs are made of sheets of corrugated iron and flooring is often dirt. The majority of homes have piped water, but most have only one faucet, and water is sometimes rationed at certain times of day. Hence, people keep water in buckets and water tanks for use in different areas of the house, as well as 
in preparation for routine water rationing or shortages. MINSA has reported the presence of $A$. aegypti in Villa El Salvador since 2005 and, notably, the neighbouring district of Villa Maria del Triunfo was the site of a substantial outbreak of dengue in 2013. ${ }^{1030}$

\section{Study design}

Four local, experienced field workers applied a crosssectional survey to households from Oasis in 2013, which comprises of approximately 120 blocks. To ensure spatial distribution of the houses surveyed, we aimed to recruit three houses per block. Using field maps, field workers selected the first house at random and performed doorto-door sequential surveying. If a house was closed, they moved to the house next door, until three households had been recruited. If less than three households were recruited and all remaining houses declined to participate or were closed, field workers moved to the next block. If more than one adult was present, the field worker requested to speak with the adult most likely to be a caregiver in the household. Unfortunately, we did not document the number of houses that refused to participate, nor the number of closed homes at time of recruitment.

\section{Inclusion criteria}

Survey participation was completed by one adult member of the household between the age of 18 and 80 years, with verbal consent, as approved by institutional review boards.

\section{Study instrument}

The survey was adapted from an existing KAP survey previously used in Iquitos, Peru. ${ }^{26}$ The survey was piloted on 19 people and modified slightly to suit the local study population. The questions on the paper-based survey were mostly closed-ended, with pre-established response categories. After questions regarding respondents' sociodemographic characteristics, we focused on knowledge of dengue: its symptoms, transmission, treatment and current mosquito control practices. Each survey took approximately $40 \mathrm{~min}$ and was conducted in Spanish.

\section{Patient and public involvement}

To help design and implement this study, we used data available from a dengue-related KAP study carried out in Iquitos, by members of our team. The engagement with the community during this process informed many of the methodological approaches taken here. The local participants were not directly involved in the design, recruitment or implementation of this study; however, they were given time at the end of each survey to address any dengue specific questions that could help improve their understanding of the disease. We do not plan to directly disseminate the results of this study to the community but hope that its contribution to the scientific literature can help inform public health bodies in their communitybased work.

\section{Data analysis}

Data collected from the household surveys were entered into a Microsoft Excel 2010 V.14.0 (Microsoft, Redmond, Washington, USA) spreadsheet, using double data entry. Surveys were coded using a numerical sequence, and no patient identifiable data were recorded. R V.3.6.1 was used to clean and analyse all data. ${ }^{31}$ Responses to questions with an open-ended 'other' option were reviewed, and new response categories were created if common and relevant themes were identified. We reported frequencies for categorical variables and medians for continuous variables. $\chi^{2}$ tests examined associations between question responses and gender. Missing data were not imputed, and denominators were adjusted accordingly.

Six logistic regression models were conducted, each using different binary dependent variables. Models 1-4 examine factors associated with knowledge of dengue and models 5 and 6 examine factors associated with current mosquito control practices. The models' dependent and independent variables are described below.

Dependent variables

- Model 1: knowledge of dengue symptoms, defined as: knowledge of fever/chills plus one other correct symptom (body/joint pain, headache/eye pain, rash or malaise).

- Model 2: knowledge of dengue transmission, defined as knowing that dengue is transmitted by a mosquito.

- Model 3: knowledge of the importance of covering water containers to help prevent dengue.

- Model 4: in order to measure an overall 'good' knowledge of dengue, the fourth model used a composite of knowing at least two outcome variables from models $1-3$.

- Model 5: carrying out any action with the intention of controlling mosquitoes in the home for whatever reason.

- Model 6: being in the top $25 \%$ of annual spenders on mosquito control products. Our hypothesis was that people with higher income or higher education may be more willing to spend more on mosquito control products such as coils or insecticide sprays than their counterparts.

Independent variables

- Age, as a binary variable cut at the median age of 40 years.

- Sex.

- Attendance or previous attendance of post high school education, such as university or technical training, as a binary variable.

- High income, as a binary variable, defined as a household income of $>\$ 5000$ annually.

- The presence of a child 5 years or younger in the house, as a binary variable. Children less than 5 years do not generally attend school, and we hypothesised having a child in the home during the day might have a greater influence on preventive practices.

- For models 5 and 6, to examine whether knowledge of dengue itself was associated with practices, we 


\begin{tabular}{|c|c|}
\hline Characteristic & Value \\
\hline Age median (IQR) & $40.0(30-46)$ \\
\hline \multicolumn{2}{|l|}{$\operatorname{Sex} \%(n / d)^{*}$} \\
\hline Female & $80.0(192 / 240)$ \\
\hline Male & $20.0(48 / 240)$ \\
\hline \multicolumn{2}{|l|}{ Education level reached \% (n/d) } \\
\hline Primary & $32.1(77 / 240)$ \\
\hline Secondary & $46.2(111 / 240)$ \\
\hline Technical or university & $21.6(52 / 240)$ \\
\hline \multicolumn{2}{|l|}{ Occupation \% (n/d) } \\
\hline Housewife & $51.7(124 / 240)$ \\
\hline Sales & $14.2(34 / 240)$ \\
\hline Unskilled & $7.1(17 / 240)$ \\
\hline Student & $6.3(15 / 240)$ \\
\hline Unemployed & $1.2(4 / 240)$ \\
\hline Other & $19.2(46 / 240)$ \\
\hline \multicolumn{2}{|l|}{ Annual household income US\$ \% (n/d) } \\
\hline $0-499$ & $17.5(40 / 229)$ \\
\hline 500-999 & $38.4(88 / 229)$ \\
\hline 1000-4999 & $15.7(36 / 229)$ \\
\hline $5000+$ & $28.4(65 / 229)$ \\
\hline \multicolumn{2}{|l|}{ Household information } \\
\hline $\begin{array}{l}\text { People per household median } \\
\text { (IQR) }\end{array}$ & $5(4-6)$ \\
\hline $\begin{array}{l}\text { Households with child }<5 \text { years } \% \\
(n / d)\end{array}$ & $46.7(112)$ \\
\hline
\end{tabular}

${ }^{*} \mathrm{n}=$ number of people answering affirmatively; $d=$ number of people who answered the question. Where the denominator is less than expected, this represents missing values due to participants choosing not to answer certain questions.

$I Q R$, interquartile range.

also included the dependent variable from model 4 (composite score of 'good knowledge').

We performed logistic regression models using the 'glm' function from the 'stats' package in $\mathrm{R}$ and used base $\mathrm{R}$ functions to calculate adjusted ORs and $95 \%$ CIs. We looked for the presence of multicollinearity between independent variables in the models by calculating the variance inflation factor (VIF) using the 'vif' function from the 'car' package in R. For each model, we present the maximum VIF of the model's independent variables. With a maximum VIF $<5$ not highly suggestive of the presence of multicollinearity. Furthermore, we calculated McFadden's $\mathrm{R}^{2}$ as a measure of model fit.

\section{RESULTS}

\section{Population}

A total of 240 surveys were completed, $80 \%$ of respondents were female and the median age was 40 years (table 1). Approximately half of respondents (51.7\%) were housewives (table 1 ). The next most common professions were sales $(14.2 \%)$, unskilled work $(7.1 \%)$ and $6.3 \%$ were full-time students (table 1). Almost half of respondents $(46.2 \%)$ had some level of secondary education, and almost a fifth $(21.6 \%)$ had at least some technical programme or university education (table 1 ). Due to the informal nature of employment, respondents were asked to estimate from various income brackets. Most respondents $(38.4 \%)$ reported annual household incomes of $\$ 500-\$ 999$ (table 1). The majority of respondents owned their homes $(69.6 \%)$ and had electricity $(97.9 \%)$ and piped water $(93.3 \%)$ in the home.

\section{Knowledge: general}

Most respondents (97.9\%) had heard of dengue, and $95.1 \%$ correctly believed there had been dengue cases in Lima (table 2). Despite this, only 6.2\% knew someone who had previously had dengue (table 2).

\section{Knowledge: symptoms}

Although $80.0 \%$ knew that fever and/or chills were symptoms of dengue, only $51.7 \%$ of respondents were able to identify an additional correct symptom (body/joint pain, headache/eye pain, rash or malaise) (table 2). Model 1 (table 3) showed that variables significantly associated with correctly identifying classic dengue symptoms were: female sex (OR 2.22, 95\% CI 1.08 to 4.72 ), attendance of higher education (OR 2.56, 95\% CI 1.25 to 5.44 ) and presence of a child $\leq 5$ years old in the house (OR 3.16, $95 \%$ CI 1.74 to 5.86 ).

\section{Knowledge: transmission}

Approximately half of the respondents (54.2\%) knew dengue is transmitted by a mosquito (table 2), with only $1.7 \%$ of respondents naming the mosquito species, $A$. aegypti. Additionally, $18.3 \%$ of respondents reported believing dengue is transmitted through water and $12.5 \%$ implicated the mosquito egg as the infectious agent. Another $1.7 \%$ believed DENV is transmitted through person-person contact. Model 2 (table 3) showed that having attended higher education was significantly associated with knowing that dengue was transmitted by a mosquito (OR $3.46,95 \%$ CI 1.69 to 7.57 ).

\section{Knowledge: treatment}

Only $25.0 \%$ of individuals listed an appropriate treatment for dengue (ie, taking paracetamol, oral rehydration or going to a health clinic), whereas $17.1 \%$ reported an inappropriate treatment of symptoms, such as antibiotics or vaccination, and the remaining $57.9 \%$ did not know or did not give an answer.

\section{Knowledge: prevention}

Approximately two-thirds of individuals (66.7\%) knew that covering water containers is an effective measure to prevent dengue. Other actions that were believed to reduce dengue were cleaning inside the home $(60.4 \%)$, use of purchased products (sprays, coils and bleach) 
Table 2 Key survey responses by gender

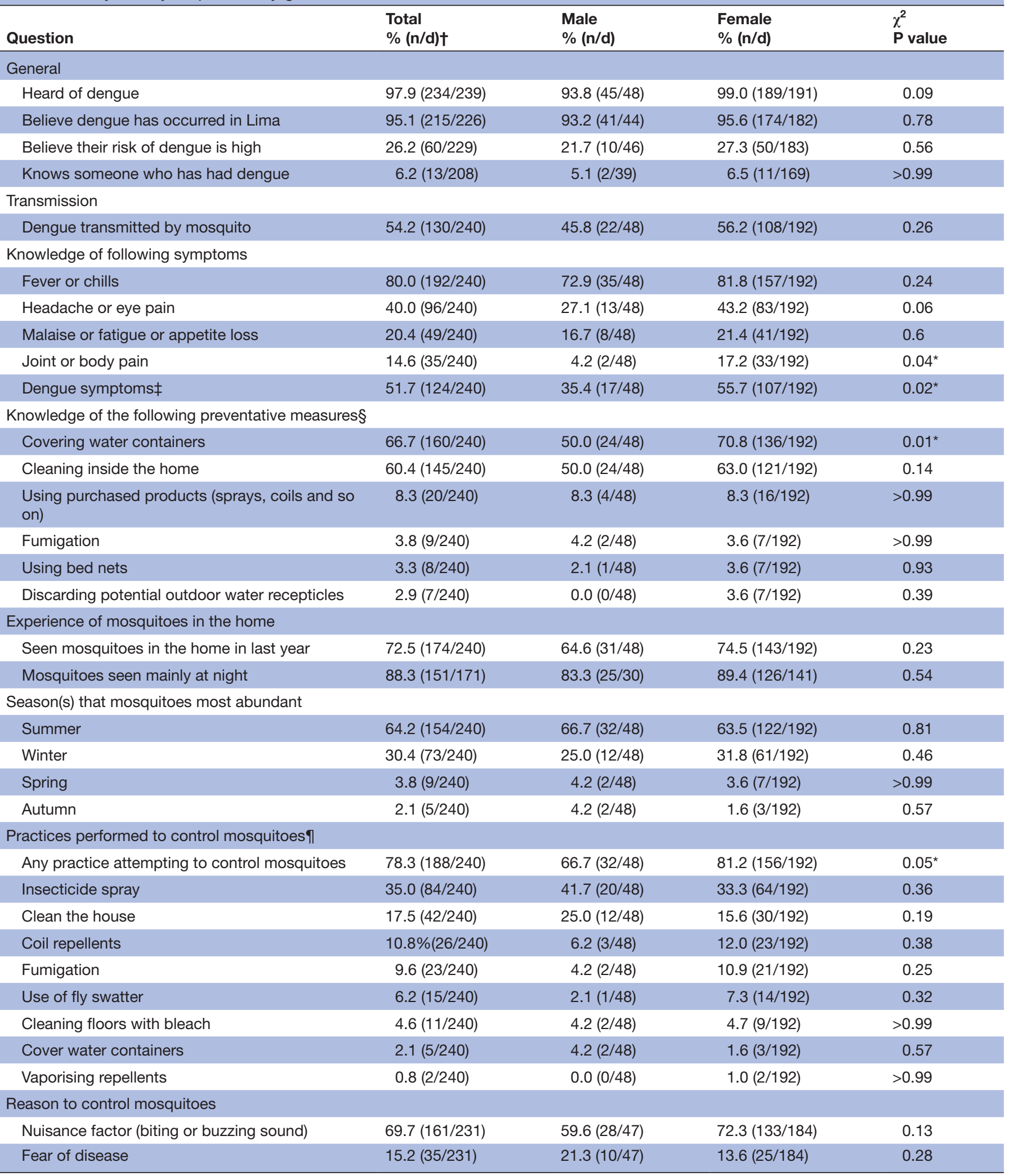

$\dagger \mathrm{t}=$ number of people answering affirmatively; $d=$ number of people who answered the question. Where the denominator is less than expected, this represents missing values due to participants choosing not to answer certain questions.

†Respondents correctly identified fever/chills and at least one of the following: malaise/fatigue/anorexia, joint/body pain, head/eye pain and rash. $\S$ This is knowledge of the action and does not imply the action is actually carried out.

१These are actions actually completed by the participant. People may perform multiple actions. 
Table 3 Predictors of dengue knowledge

\begin{tabular}{|c|c|c|c|c|}
\hline & Model 1 & Model 2 & Model 3 & Model 4 \\
\hline Predictors & $\begin{array}{l}\text { Symptoms } \\
\text { OR (95\% Cl) }\end{array}$ & $\begin{array}{l}\text { Transmission } \\
\text { OR }(95 \% \mathrm{CI})\end{array}$ & $\begin{array}{l}\text { Prevention } \\
\text { OR }(95 \% \mathrm{CI})\end{array}$ & $\begin{array}{l}\text { Overall } \\
\text { OR (95\% CI) }\end{array}$ \\
\hline $\operatorname{Sex}(f)$ & 2.22 (1.08 to 4.72 ) & 1.82 (0.91 to 3.69$)$ & $2.12(1.06$ to 4.21$)$ & 3.29 (1.63 to 6.87 ) \\
\hline Higher education & 2.56 (1.25 to 5.44$)$ & 3.46 (1.69 to 7.57$)$ & 0.55 (0.27 to 1.09$)$ & 2.43 (1.16 to 5.39$)$ \\
\hline McFadden's $\mathrm{R}^{2}$ & 0.14 & 0.09 & 0.08 & 0.12 \\
\hline Maximum VIF† & 1.19 & 1.18 & 1.15 & 1.18 \\
\hline
\end{tabular}

*Multiple logistic regression models demonstrating factors associated with knowledge of dengue, $p<0.05$. See methods for description of dependent variables.

TVIF=these are the maximum variance inflation factor of all the independent variables in the model. High VIF values $(>5)$ indicate the presence of multicollinearity between independent variables. As the maximum detected VIF was $<5$, multicollinearity is not likely to be present in these models.

$(8.3 \%)$, fumigation $(3.8 \%)$ and use of bed-nets $(3.3 \%)$ (table 2). Model 3 (table 3) showed that female sex was significantly associated with knowing the importance of covering water containers for prevention (OR 2.12, 95\% CI 1.06 to 4.21 ).

\section{Knowledge: overall}

Model 4 (table 3) assessing overall knowledge of dengue (symptoms and/or transmission and/or prevention) showed that female sex (OR 3.29, 95\% CI 1.63 to 6.87) and attendance of higher education (OR 2.43, 95\% CI 1.16 to 5.39) were significantly associated with overall knowledge of dengue.

\section{Experience of mosquitoes in the home (not specific to $A$. aegypti)}

The majority of respondents $(72.5 \%)$ reported having seen mosquitoes in the home in the last year. Of these, $88.3 \%$ said they mainly notice being bitten by mosquitoes throughout the night (between 20:00 and 05:00). People most commonly reported seeing mosquitoes during the summer months (64.2\%) (table 2).

\section{Attitudes}

Most respondents believed they are at low or no risk for contracting DENV $(73.8 \%)$. The most common reason for controlling mosquitoes in homes was the nuisance of mosquito bites or the annoyance of the buzzing sound of the mosquito $(69.7 \%)$. Only $15.2 \%$ said they attempted to control mosquitoes due to fear of disease (table 2). Respondents decide which mosquito products to buy based on perceived effectiveness or quality $(38.8 \%)$ or what they feel best protects against disease $(11.2 \%)$.

\section{Current practices}

Purchased products used in an attempt to control mosquitoes included: insecticide sprays $(35.0 \%)$, coil repellents $(10.8 \%)$ and bleach applied to internal floors $(4.6 \%)$. An additional $21.7 \%$ of respondents reported doing nothing to reduce mosquitoes. Despite $66.7 \%$ of people knowing that covering external water containers may prevent dengue, only five respondents $(2.1 \%)$ said they actually cover water containers as practice against mosquitoes. The median estimated annual spend on mosquito control products was $\sim 13$ PEN (IQR $0-65$ ) or $\sim 3.8$ US\$ (IQR 0-19.6). Age (OR 2.19, 95\% CI 1.05 to 4.70 ) and the presence of a child $\leq 5$ years (OR 2.38, 95\% CI 1.13 to $5.20)$ were significantly associated with doing anything to control mosquitoes (table 4, model 5). Model 6 (table 4) showed no significant predictors of being in the top $25 \%$ of spenders on mosquito control products.

Table 4 Predictors of mosquito control practices

\begin{tabular}{|c|c|c|}
\hline & Model 5 & Model 6 \\
\hline Predictors & $\begin{array}{l}\text { Mosquito control } \\
\text { OR }(95 \% \mathrm{Cl})\end{array}$ & $\begin{array}{l}\text { Top } 25 \% \\
\text { spenders } \\
\text { OR }(95 \% \mathrm{CI})\end{array}$ \\
\hline Age (>40years) & 2.19 (1.05 to 4.70$)$ & 1.08 (0.56 to 2.08$)$ \\
\hline $\operatorname{Sex}(f)$ & $1.71(0.74$ to 3.83$)$ & $0.93(0.42$ to 2.15$)$ \\
\hline Higher education & 2.47 (0.98 to 7.23$)$ & 1.15 (0.53 to 2.41$)$ \\
\hline $\begin{array}{l}\text { Child } \leq 5 \text { years in } \\
\text { house }\end{array}$ & 2.38 (1.13 to 5.20$)$ & $1.60(0.83$ to 3.10$)$ \\
\hline High income & $1.35(0.62$ to 3.15$)$ & 1.47 (0.75 to 2.81$)$ \\
\hline Good knowledge & $1.76(0.87$ to 3.54$)$ & 1.67 (0.85 to 3.35$)$ \\
\hline McFadden's $R^{2}$ & 0.15 & 0.06 \\
\hline Maximum VIF† & 1.21 & 1.17 \\
\hline
\end{tabular}

*Multiple logistic regression models demonstrating factors associated with practices to control mosquitoes, $p<0.05$ $+\mathrm{VIF}=$ these are the maximum variance inflation factor of all the independent variables in the model. High VIF values $(>5)$ indicate the presence of multicollinearity between independent variables. As the maximum detected VIF was $<5$ multicollinearity is not likely to be present in these models. 


\section{DISCUSSION}

Despite dengue being uncommon in Lima, this population demonstrated some baseline knowledge with $97.9 \%$ of people having heard of dengue and $80 \%$ associating the disease with fever. Of our participants, $54.2 \%$ were aware that the disease is transmitted by mosquitoes. This is slightly less than reported in the KAP carried out by MINSA in 2004 on residents of Lima and similar to data from a KAP survey carried out in the Ica province south of Lima in $2010(40 \%-58 \%)$ but substantially less than in Iquitos $(86 \%)$ where dengue is endemic. ${ }^{96}{ }^{32}$ While individuals living in endemic regions have more exposure to public health campaigns, most also have a more personal connection with the disease having either had the disease themselves or knowing someone who has, strongly reinforcing knowledge of the disease. The Iquitos KAP revealed that knowledge of dengue was significantly associated with knowing someone who had previously had dengue in the past. ${ }^{26}$ In our study, only $6.2 \%$ of individuals knew somebody who had previously experienced dengue, compared with $65 \%$ in Iquitos.

Despite this baseline knowledge, many individuals had an incomplete understanding of disease transmission. For example, approximately a third of people were aware of the connection with water or insect eggs, but many suggested the presence of contaminated water or the contamination of water with insect eggs as being responsible for transmission. One individual stated 'pone el huevo en el agua y si tomas nos contaminamos con el dengue' implying the following understanding: drinking water with eggs (presumably placed by a mosquito or other insect) can transmit dengue, and this was a common theme (online supplementary file S1).

Consistent with the Iquitos KAP survey and those in other endemic countries, we found that higher education levels and female sex were significantly associated with a better knowledge of dengue (symptoms, prevention and overall knowledge). ${ }^{2633}$ Eighty per cent of respondents in our sample were women, probably due to lower rates of employment among women compared with men in Peru with women more likely to be home at the time of the interviews. ${ }^{34}$ Also, the Peruvian MINSA deploys community health workers (CHWs) to disseminate dengue knowledge through door to door visits. ${ }^{25} 35$ Knowledge in women could be higher as they are more likely to encounter CHWs during the day and because they are likely to be implementing any practical steps associated with dengue prevention. While directing dengue prevention campaigns to those that manage households seems a sensible approach, using other methods of communication such as social media, television and radio could disseminate information to those not at home during the day, broadening coverage. MINSA are currently running a campaign called 'Mi casa sin zancudos' (My house without mosquitoes) using social media and advertisements (figure 2) ${ }^{25}$ Measuring the effectiveness of these approaches would require a different methodology to

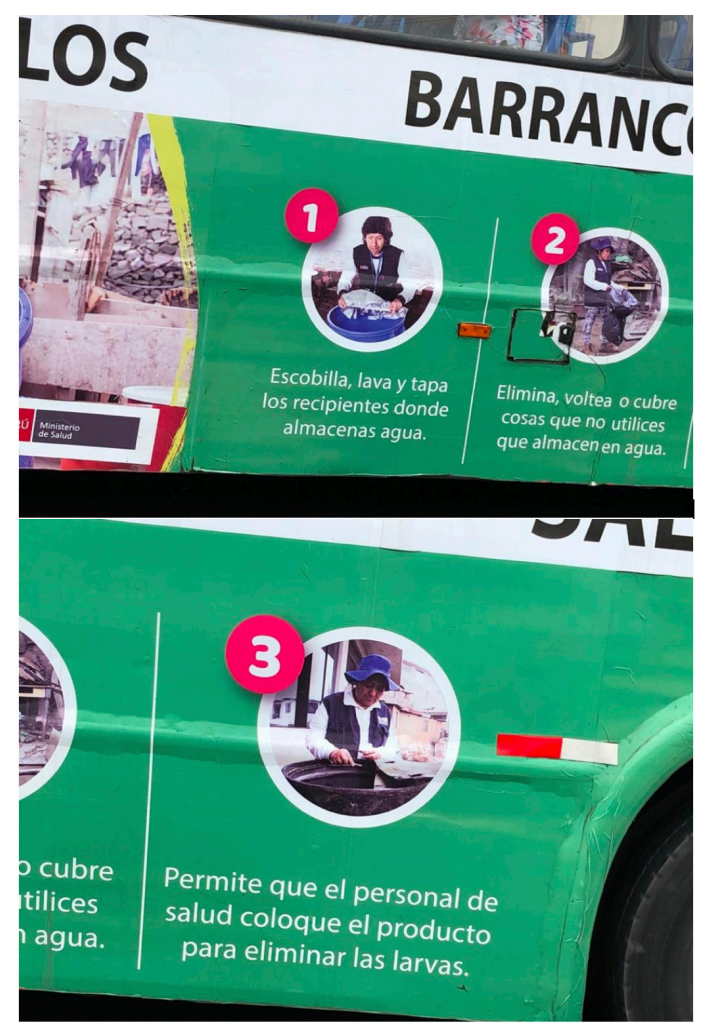

Figure 2 Photographs of current government lead campaign 'Mi Casa Sin Zancudos' on bus in Chorillos district of Lima.

that taken in this study and is an important consideration for future studies.

Given the sporadic nature of DENV transmission in Lima, we would not expect people's practices to be driven by fear of this disease. Indeed, most people $(73.8 \%)$ believed they were at no or low risk of dengue. This attitude is consistent with the findings that most people $(67.1 \%)$ reported carrying out mosquito control practices due to the nuisance of mosquitoes rather than disease prevention and that despite approximately two-thirds of people being aware of the importance of covering water containers, only a very small minority $(2.1 \%)$ actually do so. We did not find an association between dengue knowledge and mosquito control practices (models 5 and 6). However, even studies in endemic countries examining this association have shown mixed results, suggesting that factors other than dengue knowledge and endemicity play a role in the use of mosquito control practices. ${ }^{1820}$ As nuisance biting tends to be experienced at night, it would be important to reinforce the message that $A$. aegypti mosquitoes are predominantly day biters and therefore measures to reduce nuisance biting are not necessarily highly effective in preventing dengue.

Notably, the presence of children 5 years and under in a household was also significantly associated with household members reporting that they carry out measures to control mosquitoes possibly out of parental concern for their young children's health, this was similarly found to be the case in the dengue-endemic city of Iquitos. ${ }^{26}$ 
Children may react more strongly to mosquito bites than adults, seeing a child with inflamed itchy bites that cause discomfort and prevent them from sleeping could be a strong motivation to prevent bites. ${ }^{36}$

We recognise some limitations to this study including its relatively small sample size from only one location in Lima. Although Oasis is not dissimilar from many parts of Lima and general lessons can be taken, extrapolating these results to other populations should be done with caution. Unfortunately, we did not collect data on the number of households or individuals that refused to participate; thus, we are unable to assess the response rate in our population and whether refusal to participate may have introduced any selection bias. Furthermore, houses were only visited during the day and thus most professional working routine office hours would have been excluded from participating. This is reflected in the female-to-male ratio of $4: 1$ of our sample.

Translating knowledge of dengue into appropriate community action in places like Lima where transmission is likely to increase will be a challenge for the future. Understanding people's current KAP is important for guiding public health interventions. Although there seems to be a baseline understanding of dengue, knowledge of how the disease is transmitted could be strengthened. Communicating campaign information to those that manage households (predominantly women in this population) has obvious advantages, but reaching out to those not at home in the day time could help broaden community knowledge of the disease. In line with the WHO's IVM approach to the control of vector-borne disease, entomological and disease surveillance systems need to be strong so that public health campaigns in locations like Lima can be timed well and target the correct populations.

Acknowledgements We would like to express our thanks to the field workers and data entry personnel at the PRISMA (local non-governmental organisation) field office in Pampas San Juan de Miraflores for all assistance in data collection and data entry. We would also like to take this opportunity to thank all participants in this study for sharing their valuable time with us.

Contributors The study was conceived and designed by VP-S, RO, MK-M and FJ. Data collection was carried out by MK-M with support of local field staff. Supervision of field staff was led by LNC with the support of VP-S. Data were analysed and interpreted by WHE and EO with support from VP-S. Drafting and revision of the manuscript were carried out by WHE, EO and VP-S. All authors reviewed and gave approval to the final submitted manuscript.

Funding This study was funded by the National Institute on Minority Health and Health Disparities ('Tulane-Xavier Minority Training in International Health'; T37 MD001424) through the Minority Health International Research Training Program.

Competing interests None declared.

Patient consent for publication Not required.

Ethics approval The Institutional Review Board approval was obtained from Tulane University School of Public Health and Tropical Medicine (315 711) and the Peruvian non-governmental organization, Asociación Benéfica PRISMA (CE0800.13).

Provenance and peer review Not commissioned; externally peer reviewed.

Data availability statement All data and R-scripts used for the analysis in this manuscript can be found at: https://github.com/hammoire/dengue_kap.

Open access This is an open access article distributed in accordance with the Creative Commons Attribution Non Commercial (CC BY-NC 4.0) license, which permits others to distribute, remix, adapt, build upon this work non-commercially, and license their derivative works on different terms, provided the original work is properly cited, appropriate credit is given, any changes made indicated, and the use is non-commercial. See: http://creativecommons.org/licenses/by-nc/4.0/.

\section{REFERENCES}

1 Bhatt S, Gething PW, Brady OJ, et al. The global distribution and burden of dengue. Nature 2013;496:504-7.

2 Messina JP, Brady OJ, Golding N, et al. The current and future global distribution and population at risk of dengue. Nat Microbiol 2019.

3 PAHO. Reported cases of dengue fever in the Americas. PAHO. Available: http://www.paho.org/data/index.php/en/mnu-topics/ indicadores-dengue-en/dengue-nacional-en/252-dengue-pais-anoen.html?showall=\&start=1 [Accessed 13 Mar 2018].

4 Pan American Health Organization (PAHO). Epidemiological update dengue, 2019. Available: https://www.paho.org/hq/index.php? option=com_topics\&view=rdmore\&cid=2217\&item=dengue\&type= alerts\&ltemid $=40734$ \&lang $=$ en

5 Stoddard ST, Wearing HJ, Reiner RC, et al. Long-term and seasonal dynamics of dengue in lquitos, Peru. PLoS Negl Trop Dis 2014;8:e3003.

6 Halsey ES, Williams M, Laguna-Torres VA, et al. Occurrence and correlates of symptom persistence following acute dengue fever in Peru. Am J Trop Med Hyg 2014;90:449-56.

7 Centro Nacional de Epidemiologia, Prevención y Control de Enfermedades -MINSA. Sala situacional para el Análisis de Situación de Salud - SE 35 - 2019. Available: https://www.dge.gob.pe/portal/ index. php?option $=$ com content\&view $=$ article\&id $=14 \& \mid$ temid $=121$

8 Ruiz EF, Vasquez-Galindo CM, Aquije-Pariona XM, et al. Outbreaks caused by Aedes aegyptis due to El Niño in a coastal area of Peru. Travel Med Infect Dis 2018;21:78-9.

9 Miranda-Soberón U, Acevedo-Villar T, León-Alejo A, et al. [Dengue in Ica: an opportunity for effective interventions]. Rev Peru Med Exp Salud Publica 2015;32:607-8.

10 Vigilancia y Control Vectorial. Distritos infestados POR Aedes aegypti a nivel nacional. Available: http://www.digesa.minsa.gob.pe/DCOVl/ infestacion.html [Accessed 14 Mar 2018].

11 Norte DL. Alerta epidemiologica. Available: http://www.dirislimanorte. gob.pe/wp-content/uploads/2018/03/Alerta-Epidemiol\%C3\% B3gica-n\%C2\%B002.pdf

12 El Comer. Cinco distritos del sur de lima están en alerta por ei dengue, 2013

13 PERU Instituto Nacional de Estadística e Informática INEI. Estadisticas. Available: https://www.inei.gob.pe/estadisticas/indicetematico/poblacion-y-vivienda/ [Accessed 15 Mar 2019].

14 World Health Organization,. Handbook for integrated vector management. Geneva: World Health Organization, 2012.

15 Castañeda O, Segura O, Ramírez AN. Knowledge, attitudes and community practice during an outbreak of dengue in a town in Colombia, 2010]. Rev Salud Publica Bogota Colomb 2011;13:514-27.

16 dos Santos SL, Cabral A. Augusto LG da S. [Knowledge, attitude and practice on dengue, the vector and control in an urban community of the Northeast Region, Brazil]. Cienc Saude Coletiva 2011;16:1319-30.

17 Alves AC, Fabbro ALD, Passos ADC, et al. Knowledge and practices related to dengue and its vector: a community-based study from Southeast Brazil. Rev Soc Bras Med Trop 2016;49:222-6.

18 Harapan H, Rajamoorthy Y, Anwar S, et al. Knowledge, attitude, and practice regarding dengue virus infection among inhabitants of Aceh, Indonesia: a cross-sectional study. BMC Infect Dis 2018;18:96.

19 Herbuela VRDM, de Guzman FS, Sobrepeña GD, et al. Knowledge, attitude, and practices regarding dengue fever among pediatric and adult in-patients in Metro Manila, Philippines. Int J Environ Res Public Health 2019;16:ijerph16234705.

20 Shuaib F, Todd D, Campbell-Stennett D, et al. Knowledge, attitudes and practices regarding dengue infection in Westmoreland, Jamaica. West Indian Med J 2010;59:139-46.

21 Sarmiento-Senior D, Matiz MI, Jaramillo-Gómez JF, et al. Knowledge, attitudes, and practices about dengue among pupils from rural schools in an endemic area in Colombia. Biomédica 2019;39:478-90.

22 Elsinga J, Schmidt M, Lizarazo EF, et al. Knowledge, attitudes, and preventive practices regarding dengue in Maracay, Venezuela. $A m \mathrm{~J}$ Trop Med Hyg 2018;99:195-203.

23 Ortiz C, Rúa-Uribe GL, Rojas CA. Knowledge, practices and entomological aspects of dengue in Medellín, Colombia: a comparative study of neighborhoods with high and low incidence. Biomedica 2018;38:106-16. 
24 Ministerio de Salud Peru, Direccion general de promocion de la salud, proyecto vigia. Conocimientos, actitudes y prácticas de la poblcaión frente al dengue: lima y macro región norte de Perú, 2004. https://cdn.www.gob.pe/uploads/document/file/392296/ Conocimientos_actitudes_y_prácticas_de_la_población_frente_al dengue_Lima_y_macro_región_norte_del_Perú20191017-26355xs4wpy.pdf

25 Peruvian Ministerio de Salud. Mi casa sin zancudos: campaña, 2019 Available: https://www.gob.pe/institucion/minsa/campañas/64-micasa-sin-zancudos

26 Paz-Soldán VA, Morrison AC, Cordova Lopez JJ, et al. Dengue knowledge and preventive practices in lquitos, Peru. Am J Trop Med Hyg 2015;93:1330-7.

27 Castro M, Sánchez L, Pérez D, et al. A community empowerment strategy embedded in a routine dengue vector control programme: a cluster randomised controlled trial. Trans $R$ Soc Trop Med Hyg 2012;106:315-21.

28 Erlanger TE, Keiser J, Utzinger J. Effect of dengue vector control interventions on entomological parameters in developing countries: a systematic review and meta-analysis. Med Vet Entomol 2008;22:203-21.

29 Andersson N, Nava-Aguilera E, Arosteguí J, et al. Evidence based community mobilization for dengue prevention in Nicaragua and Mexico (Camino Verde, the green way): cluster randomized controlled trial. BMJ 2015;351:h3267.
30 Dirección de Salud II Lima Sur. Primer brote de dengue en lima sur. Distrito de villa maría del triunfo, 2013.

31 R Core Team. R: a language and environment for statistical computing. R foundation for statistical computing, Vienna, Austria, 2018. Available: https://www.R-project.org/

32 Morrison AC, Minnick SL, Rocha C, et al. Epidemiology of dengue virus in Iquitos, Peru 1999 to 2005: interepidemic and epidemic patterns of transmission. PLoS Negl Trop Dis 2010;4:e670.

33 Kumaran E, Doum D, Keo V, et al. Dengue knowledge, attitudes and practices and their impact on community-based vector control in rural Cambodia. PLoS Negl Trop Dis 2018;12:e0006268.

34 Ministerio de Trabajo y Promoción del Empleo, Peru. Informe anual 2018: la mujer en ei mercado laboral peruano, 2018. Available: https://cdn.www.gob.pe/uploads/document/file/471959/Informe_ Anual_de_la_Mujer_2018.pdf

35 Pan American Health Organization (PAHO). Ministerio de salud inició campaña para prevenir dengue en distritos del sur de lima y continúa acciones en todo ei país, 2013. Available: https://www.paho.org/per/ index.php?option=com_content\&view=article\&id=1967:ministeriosalud-inicio-campana-prevenir-dengue-distritos-sur-lima-continuaacciones-todo-pais\&ltemid $=900$

36 Tan JW, Campbell DE. Insect allergy in children. J Paediatr Child Health 2013;49:E381-7. 